\title{
ВЛИЯНИЕ СОЕВОЙ МУКИ НА КАЧЕСТВО ПШЕНИЧНОГО ХЛЕБА
}

\author{
E.N. Efremova, E.A. Zenina,
} A.A. Shershnev

\section{THE INFLUENCE OF SOY FLOUR ON WHEAT BREAD QUALITY}

Ефремова Елена Николаевна - канд. с.-х. наук, доц. каф. перерабатывающих технологий и продовольственной безопасности Волгоградского государственного аграрного университета, г. Волгоград. E-mail: elenalob@rambler.ru

Зенина Елена Анатольевна - канд. с.-х. наук, доц. каф. перерабатывающих технологий и продовольственной безопасности Волгоградского государственного аграрного университета, г. Волгоград. E-mail: lenzsara@mail.ru

Шершнев Алексей Алексеевич - канд. С.-х. наук, доц. каф. перерабатывающих технологий и продовольственной безопасности Волгоградского государственного аграрного университета, г. Волгоград. E-mail: elenalob@rambler.ru

Ведущие фрирмы-производители хлебобулочных изделий уделяют большое внимание поиску эфрфективных способов расширения ассортимента. Основным направлением в решении этой задачи является разработка хлебобулочных изделий целевого назначения, 8 частности рецептур разных сортов лечебнодиетического хлеба из новых видов сырья. Рассматривается применение соевой муки при производстве пшеничного хлеба. Цель исследования - расширение ассортимента хлебобулочных изделий с использованием соевой муки, позволяющей повысить качество и пищевую ценность пшеничного хлеба. Задачи исследования - разработать рецептуру пшеничного хлеба с добавлением соевой муки; изучить органолептические и физико-химические показатели хлеба с добавлением соевой муки; оnределить экономическую эфрфективность производства хлеба с добавлением соевой муки. Исследование и пробную выпечку хлеба проводили на базе ФГБОУ ВО ВолГАУ, каффедра «Перерабатывающие технологии и продовольственная безопасность». После выпечки
Efremova Elena Nikolaevna - Cand. Agr. Sci., Assoc. Prof., Chair of Processing Technologies and Food Security, Volgograd State Agrarian University, Volgograd.

E-mail: elenalob@rambler.ru

Zenina Elena Anatolyevna - Cand. Agr. Sci., Assoc. Prof., Chair of Processing Technologies and Food Security, Volgograd State Agrarian University, Volgograd.

E-mail: lenzsara@mail.ru

Shershnev Alexey Alexeevich - Cand. Agr. Sci., Assoc. Prof., Chair of Processing Technologies and Food Security, Volgograd State Agrarian University, Volgograd.

E-mail: elenalob@rambler.ru

хлеба проводили оценку по органолептическим и ффизико-химическим показателям. Образец с добавлением соевой муки соответствовал ГОСТ Р 58233-2018 «Хлеб из пшеничной муки». Запах был ароматный, ивет - с желтоватым оттенком, корка значительно интенсивнее окрашена. Пористость мякиша выше на $5 \%$ по сравнению с контрольным образцом. При расчете чистой прибыли от продажи она увеличивается на 0,17 руб. на 1 ед. изделия. Рентабельность продукции пшеничного хлеба с добавлением соевой муки в количестве $10 \%$ увеличилась на $2 \%$. Предлагаем для увеличения ассортимента продукции внедрить пшеничный хлеб с добавлением соевой муки в количестве $10 \%$ от массы муки.

Ключевые слова: хлебобулочные изделия, соевая мука, безопарный способ, органолептические показатели, мякиш, пористость, упек.

Leading manufacturing firms of bakery products pay much attention to looking for effective ways of their assortment expansion. The main direction in the solution of this task was the development of 
bakery products of the purpose, in particular the recipes of different grades of medical and dietary bread from new types of raw materials. The application of soy flour in the production of white bread was considered. The research objective was the expansion of the range of bakery products with using soy flour allowing increasing the quality and nutrition value of white bread. The research problems were to develop the recipe of white bread with addition of soy flour; to study organoleptic and physical and chemical indicators of bread with addition of soy flour; to define economic efficiency of production of bread with addition of soy flour. The research and test baking of bread saw off on the basis of FSBEI HE VolSAU, chair "Processing Technologies and Food Security". After bread baking the assessment on organoleptic and physical and chemical indicators was carried out. The sample with addition of soy flour corresponded to State Standard P 58233-2018 "Bread from wheat flour". The smell was fragrant, the color - with a yellowish shade, the crust was much more intensively painted. The porosity of a crumb was $5 \%$ higher in comparison with the control sample. At calculation of net profit from sale it increased by 0.17 ruble on 1 unit of the product. The profitability of white bread production with soy flour in the number of $10 \%$ increased by $2 \%$. White bread with the addition of $10 \%$ of soy flour to the mass of the flour was suggested to be introduced for the increase in the product assortment.

Keywords: bakery products, soy flour, sugarfree method, organoleptic parameters, crumb, porosity, loss.

Введение. В последние годы для улучшения потребительских свойств хлебобулочных изделий стали использоваться новые виды дополнительного сырья. В хлебопечении это является нетрадиционным видом сырья, которое позволит повысить пищевую ценность хлеба и улучшит физико-химические показатели выпускаемых изделий, а также заменит в дальнейшем традиционное дополнительное сырье [1].

Чтобы увеличить покупательский спрос на выпускаемые изделия, необходимо улучшать рецептуру хлеба и хлебобулочных изделий, получая более полезный хлеб для здоровья населения. Чаще всего производители стали вводить в традиционную рецептуру различные улучшители качества и дополнительное сырье для обогащения хлебобулочных изделий [2] .

Перспективным сырьем для производства хлебобулочных изделий с повышенным содержанием белка является соевая мука. В муке сои также содержится большое количество витаминов, минеральных веществ, пищевых волокон и липидов, которые необходимы для нормальной жизнедеятельности человека. С ее помощью повышается пищевая ценность выпускаемого продукта.

Соевая мука получила широкое распространение в пищевой промышленности. Хлеб с добавлением соевой муки в зависимости от рецептуры может содержать на 55 \% больше белка, чем в традиционном хлебе; если добавить соевую муку в пшеничный хлеб, то в нем может быть достигнут оптимальный аминокислотный баланс $[3,4]$.

Соевый белок хорошо усваивается организмом человека и обладает лечебными свойствами при онкологических заболеваниях, сахарном диабете, аллергии, а также снижает уровень холестерина в крови и повышает иммунитет.

Добавление соевой муки в хлебобулочные изделия позволяет сократить использование основного сырья, что приводит к уменьшению себестоимости продукции [5].

Цель исследования: расширение ассортимента хлебобулочных изделий с использованием соевой муки, позволяющей повысить качество и пищевую ценность пшеничного хлеба.

Исходя из поставленной цели, необходимо решить следующие профессиональные задачи: разработать рецептуру пшеничного хлеба с добавлением соевой муки; изучить органолептические и физико-химические показатели хлеба с добавлением соевой муки; определить экономическую эфффективность производства хлеба с добавлением соевой муки.

Объектом исследования был пшеничный хлеб с добавлением соевой муки.

Методы исследования. Нормативной базой исследования было законодательство Российской Федерации о стандартизации и сертификации, нормативные документы (ГОСТы, ТУ). Анализ органолептических показателей проводили по ГОСТ 5667-65. Определение фризикохимических показателей проводили через 12 ч 
после выпечки по ГОСТ 5669-96, ГОСТ 5670-96, ГОСТ 21094-75.

Исследование и пробную выпечку хлеба проводили на базе ФГБОУ ВО ВолГАУ, кафедра «Перерабатывающие технологии и продовольственная безопасность». При производстве хлеба следует уделять большое внимание качеству используемого сырья. Из зерна сои в соответствии ГОСТ 3898-56 вырабатывается соевая мука дезодорированная трех видов: необезжиренная, полуобезжиренная и обезжиренная, - которые бывают только двух сортов высшего и первого [6].

При выпечке использовали муку соевую дезодорированную полуобезжиренную. Соевая мука имела желтоватый оттенок, запах свойственный дезодорированной муке, без постороннего запаха, без постороннего привкуса и хруста [6].

Результаты исследования. При разработке рецептуры и режиме приготовления хлеба с добавлением соевой муки за основу взяли приготовление пшеничного хлеба безопарным спосо- бом. За основу рецепта пшеничного хлеба был взят «Сборник рецептур на хлебобулочные изделия, вырабатываемые по государственным стандартам (1998 г.)», разработанный Государственным научно-исследовательским институтом хлебопекарной промышленности [7].

В исследовании было решено провести анализ пшеничного хлеба с добавлением соевой муки в количестве 5, 10 и $15 \%$ от массы муки. В результате оценки органолептических и физикохимических показателей экспериментальных образцов хлеба был выделен образец с добавлением соевой муки в количестве $10 \%$.

Образец с добавлением соевой муки в количестве $5 \%$ не имел существенных отличий по сравнению с контрольным образцом. При внесении $15 \%$ соевой муки тесто получилось сухим, рассыпчатым, а его подъемная сила была значительно снижена.

Результаты органолептической оценки пшеничного хлеба и хлеба с добавлением соевой муки представлены в таблице 1.

Таблица 1

\section{Органолептические показатели качества пшеничного хлеба}

\begin{tabular}{|c|c|c|}
\hline Показатель & Пшеничный хлеб & $\begin{array}{c}\text { Пшеничный хлеб с добавлением } \\
\text { соевой муки } 10 \%\end{array}$ \\
\hline \multicolumn{3}{|c|}{ Внешний вид } \\
\hline Форма & $\begin{array}{c}\text { Соответствующая хлебной форме, } \\
\text { в которой производилась выпечка, } \\
\text { без боковых выплывов }\end{array}$ & $\begin{array}{c}\text { Соответствующая хлебной форме, } \\
\text { в которой производилась выпечка, } \\
\text { без боковых выплывов } \\
\end{array}$ \\
\hline Поверхность & $\begin{array}{l}\text { Шероховатая с выпуклой верхней } \\
\text { коркой, с наличием шва делителя }\end{array}$ & $\begin{array}{l}\text { Шероховатая с выпуклой верхней } \\
\text { коркой, с наличием шва делителя }\end{array}$ \\
\hline Цвет & Светло-желтый & Темно-коричневый \\
\hline \multicolumn{3}{|c|}{ Состояние мякиша } \\
\hline Пропеченность & $\begin{array}{c}\text { Пропеченный, не влажный на ощупь, } \\
\text { менее эластичный }\end{array}$ & Пропеченный, не липкий, эластичный \\
\hline Промесс & Без комочков & Без комочков \\
\hline Пористость & Без пустот и уплотнений & Развитая, без уплотнений, крупная \\
\hline Вкус & Свойственный данному виду изделия & С приятным вкусом \\
\hline Запах & Свойственный данному виду изделия & Ароматный \\
\hline Цвет & С серым оттенком & С желтоватым оттенком \\
\hline
\end{tabular}

Добавление соевой муки в количестве $10 \%$ является самым оптимальным для обогащения хлеба без ухудшения качества теста и готового изделия.
Оценка пробной выпечки показала, что пшеничный хлеб с добавлением соевой муки $10 \%$ вызывает следующие изменения в процессе приготовления теста и качества готового изде- 
лия. Расстойка тестовых заготовок протекает быстрее обычного, мякиш пшеничного хлеба с соевой мукой приобретает специфический желтоватый оттенок. Повышается эластичность мякиша экспериментального образца, тем самым снижается способность к черствению у готовых изделий. Мякиш экспериментального образца эластичный, пористость развитая, без уплотнений и крупная, с приятным вкусом, ароматный.
Цвет пшеничного хлеба с добавлением соевой муки - темно-коричневый.

Корка у хлеба, с добавлением соевой муки значительно интенсивнее окрашена. Результаты пробной выпечки показали, что хлеб с добавлением соевой муки по качественным характеристикам выше, чем пшеничный хлеб.

Физико-химические показатели испытуемой продукции представлены в таблице 2.

Таблица 2

Физико-химические показатели пшеничного хлеба

\begin{tabular}{|l|c|c|}
\hline \multicolumn{1}{|c|}{ Показатель } & Пшеничный хлеб & $\begin{array}{c}\text { Пшеничный хлеб с добавлением } \\
\text { соевой муки 10 \% }\end{array}$ \\
\hline Влажность мякиша, \% & 43,0 & 44,0 \\
\hline Кислотность мякиша, град. & 2,9 & 2,8 \\
\hline Пористость мякиша, \% & 75,0 & 80,0 \\
\hline
\end{tabular}

Все показатели по фризико-химической оценке экспериментального образца изменялись. Пористость мякиша хлеба с добавлением соевой мукой увеличилась на $5 \%$, что составило $80 \%$. Кислотность мякиша хлеба с добавлением соевой муки понизилась на 0,1\%. Пищевая ценность в 100 г пшеничного хлеба: белки 7,9 г, жиры - 1 г, углеводы - 48 г. Энергетическая ценность - 223 ккал. Пищевая ценность в
100 г пшеничного хлеба с добавлением соевой муки 10 \%: белки - 23 г; жиры - 4; углеводы 30 г. Энергетическая ценность - 242 ккал.

Пшеничный хлеб с добавлением соевой муки соответствует ГОСТ Р 58233-2018 «Хлеб из пшеничной муки» [8].

В таблице 3 представлены данные по выходу хлеба пшеничного.

\section{Выход хлеба из пшеничной муки}

\begin{tabular}{|l|c|c|}
\hline \multicolumn{1}{|c|}{ Показатель } & Пшеничный хлеб & $\begin{array}{c}\text { Пшеничный хлеб с добавлением } \\
\text { соевой муки 10 \% }\end{array}$ \\
\hline Объемный выход хлеба & 143,6 & 146,3 \\
\hline Масса тестовой заготовки, г & 0,59 & 0,59 \\
\hline Масса хлеба, г & 0,5 & 0,5 \\
\hline Упек, \% & 10,0 & 9,0 \\
\hline
\end{tabular}

Объемный выход хлеба с добавлением соевой муки увеличился, при этом упек уменьшился на $1 \%$. Масса тестовой заготовки и масса хлеба после выпечки осталась неизменной.

По всем органолептическим и фризикохимическим показателям хлеб пшеничный с добавлением соевой муки 10 \% повышает белковую ценность готового изделия, а также улучшает качество хлеба и придает ему приятный аромат.
Результат эфффективности производства хлебобулочных изделий и их дальнейшая реализация оценивается по системе показателей (табл. 4-6).

Следует заметить, что затраты на сырье по опытному варианту больше контрольного варианта на 20,8 руб., или $1 \%$. Данное увеличение затрат связано с введением соевой муки в экспериментальную рецептуру. 
Затраты по рецептуре хлеба пшеничного (в расчете на 100 кг муки)

\begin{tabular}{|c|c|c|c|c|c|}
\hline \multirow{2}{*}{ Сырье } & \multirow{2}{*}{$\begin{array}{l}\text { Цена } 1 \text { кг, } \\
\text { руб. }\end{array}$} & \multicolumn{2}{|c|}{ Пшеничный хлеб } & \multicolumn{2}{|c|}{$\begin{array}{c}\text { Пшеничный хлеб с добавлением } \\
\text { соевой муки } 10 \% \\
\end{array}$} \\
\hline & & КГ & руб. & $\mathrm{K} \Gamma$ & руб. \\
\hline $\begin{array}{l}\text { Мука пшеничная хлебопе- } \\
\text { карная первого сорта }\end{array}$ & 14,20 & 100 & 1420,00 & 90 & 1278,00 \\
\hline Мука соевая & 17,00 & - & - & 10 & 170,00 \\
\hline $\begin{array}{l}\text { Дрожжи хлебопекарные } \\
\text { прессованные }\end{array}$ & 45,00 & 2,0 & 90,00 & 2,0 & 90,00 \\
\hline $\begin{array}{l}\text { Соль поваренная } \\
\text { пищевая «Экстра» }\end{array}$ & 3,90 & 1,5 & 5,85 & 1,5 & 5,85 \\
\hline Сахар-песок & 23,00 & 2 & 46,00 & 2 & 46,00 \\
\hline Масло растительное & 65,00 & 6,0 & 390,00 & 6,0 & 390,00 \\
\hline Вода питьевая & 3,60 & 60,0 & 216,00 & 58,0 & 208,80 \\
\hline Итого & & 171,5 & 2167,85 & 169,5 & 2188,65 \\
\hline Выход & & 143,6 & & 146,3 & \\
\hline
\end{tabular}

Затраты на производство хлеба пшеничного

Таблица 5

\begin{tabular}{|l|c|c|}
\hline \multicolumn{1}{|c|}{ Показатель, руб. } & Пшеничный хлеб & $\begin{array}{c}\text { Пшеничный хлеб с добавлением } \\
\text { соевой муки 10 \% }\end{array}$ \\
\hline Затраты на сырье & 2167,85 & 2188,65 \\
\hline Оплата труда с отчислениями & 360,00 & 360,00 \\
\hline Амортизация основных средств & 184,25 & 184,25 \\
\hline Коммунальные расходы & 164,84 & 164,84 \\
\hline Общепроизводственные затраты & 360,00 & 360,00 \\
\hline Прочие затраты & 150,00 & 150,00 \\
\hline Производственная себестоимость & 3386,9 & 3407,7 \\
\hline Хранение и транспортировка & 121 & 121 \\
\hline Общехозяйственные расходы & 199 & 199 \\
\hline Полная себестоимость & 3706,94 & 3727,74 \\
\hline
\end{tabular}

В полную себестоимость включены все затраты на производство хлеба пшеничного. К снижению себестоимости стремятся все предприятия. Уменьшение себестоимости является важным фактором роста прибыли и индикатором эффрективности деятельности всего предприятия в целом $[9,10]$.

Окончательную оценку экономической эффективности предприятия можно дать лишь на основе данных о размере прибыли и уровне рентабельности предприятия.
Цена определена особенностью товара и спросом на потребительском рынке. В результате улучшения базовой рецептуры хлеба, т. е. обогащением соевой мукой $10 \%$, выход хлеба составил 146,3 кг, что повлияло на полную себестоимость продукции 1 ед. изделия. Прибыль от продаж составила 0,17 руб., уровень рентабельности вырос на 2 \%, при этом технологических изменений на предприятии не требовалось. Рентабельное ведение производства признается, когда все расходы покрываются выручкой и обеспечиваются получением чистой прибыли. 


\section{Экономическая эффективность реализации пшеничного хлеба}

\begin{tabular}{|l|c|c|}
\hline \multicolumn{1}{|c|}{ Показатель } & Пшеничный хлеб & $\begin{array}{c}\text { Пшеничный хлеб с добавлением } \\
\text { соевой муки 10 \% }\end{array}$ \\
\hline Вес 1 шт. готового продукта, г & 500 & 500 \\
\hline Выход, кг/100 кг муки & 143,6 & 146,3 \\
\hline Полная себестоимость 1 шт., руб. & 12,91 & 12,74 \\
\hline Цена реализации 1 шт., руб. & 17,60 & 17,60 \\
\hline Прибыль от продажи 1 шт., руб. & 4,69 & 4,86 \\
\hline Уровень рентабельности, \% & 36 & 38 \\
\hline
\end{tabular}

Заключение. Полученные в опыте результаты отразили улучшение качественных характеристик пшеничного хлеба с добавлением соевой муки $10 \%$ от массы пшеничной муки. Хлеб с добавлением соевой муки получился более ароматнее, чем пшеничный хлеб, с желтоватым оттенком, корка хлеба интенсивнее окрашена. Пористость мякиша увеличилась на 5 \%. Выход готовой продукции хлеба пшеничного с добавлением соевой муки увеличился на $2 \%$.

Изменения органолептических и физикохимических характеристик приводят к привлекательности хлеба пшеничного с добавлением соевой муки в количестве $10 \%$ на потребительском рынке. В конечном итоге ведет к росту рентабельности реализации изделий на $2 \%$, или на 17 коп. прибыли от продажи 1 изделия.

\section{Литература}

1. Васюкова А.Т., Пучкова В.Ф. Современные технологии хлебопечения: учеб.-практ. пособие. М.: Дашков и К, 2011. 224 с.

2. Корячкина С.Я., Кузнецова Е.А., Гончаров Ю.В. Совершенствование технологии выработки хлеба из целого зерна злаковых культур // Кондитерское и хлебопекарное производство. 2006. № 10. С. 3-6.

3. Васильцов Н.В. Витаминизация хлеба актуальная задача пекарен России // Хлебопечение России. 2015. № 4. С. 28-37.

4. Калмыкова Е.В., Ефремова Е.Н. Переработка натурального растительного сырья и использование его в качестве добавок при производстве хлебобулочных изделий // Известия Нижневолжского агроуниверситетского комплекса: наука и высшее про- фессиональное образование. 2013. № 4 (32). C. 172-177.

5. Нилова Л.П. Товароведение и экспертиза зерномучных товаров: учебник. М.: ИНФРАM, 2014. 448 C.

6. ГОСТ 3898-56. Мука соевая дезодорированная. Технические условия. М.: Стандартинформ, 2006. 4 C.

7. Сборник рецептур на хлебобулочные изделия, вырабатываемые по государственным стандартам // Гос. НИИ хлебопекар. промсти. М., 1998. С. 11-12.

8. ГОСТ Р 58233-2018. Хлеб из пшеничной муки. Технические условия. М.: Стандартинформ, 2018. 15 c.

9. Ефремова Е.Н. Совершенствование рецептуры пшеничного хлеба добавками, обладающими функциональными и технологическими свойствами // Известия Нижневолжского агроуниверситетского комплекса: наука и высшее профессиональное образование. 2015. № 4 (40). С. 207-213.

10. Питюрина И.С., Евсенина М.В., Лупова Е.И. и др. Совершенствование технологии производства пшеничного хлеба функционального назначения // Вестник КрасГАУ. 2019. № 5 (146). C. 182-189.

\section{Literatura}

1. Vasjukova A.T., Puchkova V.F. Sovremennye tehnologii hlebopechenija: ucheb.-prakt. posobie. M.: Dashkov i K, 2011. 224 s.

2. Korjachkina S.Ja., Kuznecova E.A., Goncharov Ju.V. Sovershenstvovanie tehnologii vyrabotki hleba iz celogo zerna zlakovyh kul'tur // Konditerskoe i hlebopekarnoe proizvodstvo. 2006. № 10. S. 3-6. 
3. Vasil'cov N.V. Vitaminizacija hleba aktual'naja zadacha pekaren Rossii /I Hlebopechenie Rossii. 2015. № 4. S. 28-37.

4. Kalmykova E.V., Efremova E.N. Pererabotka natural'nogo rastitel'nogo syr'ja i ispol'zovanie ego $v$ kachestve dobavok pri proizvodstve hlebobulochnyh izdelij // Izvestija Nizhnevolzhskogo agrouniversitetskogo kompleksa: Nauka i vysshee professional'noe obrazovanie. 2013. № 4 (32). S. 172-177.

5. Nilova L.P. Tovarovedenie i jekspertiza zernomuchnyh tovarov: uchebnik. M.: INFRA$\mathrm{M}, 2014.448 \mathrm{~s}$.

6. GOST 3898-56. Muka soevaja dezodorirovannaja. Tehnicheskie uslovija. M.: Standartinform, 2006. $4 \mathrm{~s}$.

7. Sbornik receptur na hlebobulochnye izdelija, vyrabatyvaemye po gosudarstvennym stan- dartam // Gos. NII hlebopekar. prom-sti. M., 1998. C. 11-12.

8. GOST R 58233-2018. Hleb iz pshenichnoj muki. Tehnicheskie uslovija. M.: Standartinform, 2018. $15 \mathrm{~s}$.

9. Efremova E.N. Sovershenstvovanie receptury pshenichnogo hleba dobavkami, obladajushhimi funkcional'nymi i tehnologicheskimi svojstvami // Izvestija Nizhnevolzhskogo agrouniversitetskogo kompleksa: nauka i vysshee professional'noe obrazovanie. 2015. № 4 (40). S. 207-213.

10. Pitjurina I.S., Evsenina M.V., Lupova E.I. i dr. Sovershenstvovanie tehnologii proizvodstva pshenichnogo hleba funkcional'nogo naznachenija // Vestnik KrasGAU. 2019. № 5 (146). S. 182-189. 